\title{
Comparison of Levels of Androgenic Hormones in various Phenotypes of Polycystic Ovarian Syndrome in High School Girls aging 14 to 18 Years
}

\author{
${ }^{1}$ Marzieh Akbarzadeh, ${ }^{2}$ Tahereh Naderi, ${ }^{3}$ Mohammad H Dabbaghmaneh, ${ }^{4}$ Hamidreza Tabatabaee
}

\begin{abstract}
Introduction: Polycystic ovarian syndrome (PCOS) is the most common endocrine disorder in women. Polycystic ovarian syndrome is mainly diagnosed based on oligomenorrhea or amenorrhea accompanied by clinical or laboratory evidence of hyperandrogenemia. This study aimed to compare the levels of androgenic hormones in various phenotypes of PCOS in high school girls aged 14 to 18 years in 2009.
\end{abstract}

Materials and methods: This cross-sectional study was conducted on 3200 girl students aged 14 to 18 years. The research community included high school girls in different educational districts of Shiraz. After obtaining written informed consents, demographic questionnaire was completed and clinical signs of increased androgens (acne, hirsutism and alopecia) were recorded. In addition, ultrasound for cyst was performed for the students with menstrual disorders.

Results: The mean age of the study population was $16.17 \pm$ 1.25 years. Hyperandrogenism and polycystic ovaries phenotype compared to other phenotypes were more prevalent (45 patients, $30.8 \%$ ) in the study population. In addition, the mean testosterone, free testosterone (FT), and dehydroepiandrosterone sulfate (DHEAS) levels were higher in the patients with polycystic ovaries and hyperandrogenism. However, the results of independent t-test revealed no significant difference between the patients with polycystic ovaries and hyperandrogenism and noninfected participants regarding the mean hormone levels $(p>0.05)$. Yet, the correlation was significant in the other three phenotypes $(p<0.05)$. Moreover, 144 cases $(4.6 \%)$ suffered from oligomenorrhea, $29.5 \%$ of whom presented PCOS symptoms in the ultrasound.

Conclusion: Androgenic hormone levels were higher in the PCOS phenotypes with menstrual disorders, particularly

\footnotetext{
${ }^{1}$ Lecturer, ${ }^{2}$ Consultant, ${ }^{3}$ Professor, ${ }^{4}$ Assistant Professor

${ }^{1}$ Department of Midwifery, School of Nursing and Midwifery Maternal-Fetal Medicine Research Center, Shiraz University of Medical Sciences, Shiraz, Iran

${ }^{2}$ Department of Midwifery, School of Nursing and Midwifery, Shiraz University of Medical Sciences, Shiraz, Iran

${ }^{3}$ Department of Internal Medicine, Endocrine and Metabolism Research Center, Shiraz University of Medical Sciences, Shiraz Iran

${ }^{4}$ Department of Epidemiology, School of Health, Shiraz University of Medical Sciences, Shiraz, Iran

Corresponding Author: Marzieh Akbarzadeh, Lecturer Department of Midwifery, School of Nursing and Midwifery Maternal-Fetal Medicine Research Center, Shiraz University of Medical Sciences, Shiraz, Iran, e-mail: akbarzadm@sums.ac.ir
}

oligomenorrhea. Therefore, compared to other symptoms of hyperandrogenism and ultrasound, menstrual disorders were more important in PCOS.

Keywords: Androgen, Girls, Hormones, Phenotype, Polycystic ovarian syndrome.

How to cite this article: Akbarzadeh $M$, Naderi $T$, Dabbaghmaneh $\mathrm{MH}$, Tabatabaee $\mathrm{H}$. Comparison of Levels of Androgenic Hormones in various Phenotypes of Polycystic Ovarian Syndrome in High School Girls aging 14 to 18 Years. J South Asian Feder Obst Gynae 2016;8(1):33-39.

Source of support: Akbarzadeh $\mathrm{M}$ and Tahereh Naderi are prepared the first draft of the manuscript and Akbarzadeh $M$ made critical revisions to the paper and translated it into English language, Mohammad $\mathrm{H}$ Dabbaghmaneh supervision for diagnosis of PCOS girls, and Hamidreza Tabatabaee in the data analysis.

The research is the result of the thesis proposal by Mrs Tahrei Naderi, No. 3958, is financially supported by the Research Vice-chancellor of Shiraz University of Medical Sciences.

Conflict of interest: None

Date of received: 16 November 2015

Date of acceptance: 23 January 2016

Date of publication: March 2016

\section{INTRODUCTION}

Polycystic ovarian syndrome (PCOS) is one of the common complex endocrine disorders of the reproductive ages with variable prevalence rates and clinical presentations. ${ }^{1,2}$ The prevalence of PCOS has been reported to vary from 6 to $10 \%$ in different studies infertile women ${ }^{3-5}$ in another study. The prevalence of PCOS among adolescents was $22.5 \%$ by Rotterdam and $10.7 \%$ by Androgen Excess Society criteria. ${ }^{6}$ In Iran, the prevalence of this disorder was estimated to be $7 \%$ based on National Institute of Health (NIH) criteria and $15.2 \%$ based on Rotterdam criteria. ${ }^{7}$ Polycystic ovarian syndrome has a complex pathophysiology and its etiology is not known yet. Adult and adolescent women with hyperandrogenemia have a change in endocrine function with rapid and stable luteinizing hormone (LH) pulse frequency which results in gonadotropin releasing hormone $(\mathrm{GnRh})$ stimulation and increase in serum LH concentration, eventually leading to hyperandrogenism and ovulation disorders. ${ }^{8}$ Recent studies have also indicated that a similar abnormality is 
detected in a number of adolescents with hyperandrogenism. $^{9}$

Fruzzetti et al (2008) investigated female adolescents with PCOS and concluded that different phenotypes (oligomenorrhea, hirsutism, hyperandrogenemia, and PCOS) were associated with different metabolic disorders related to increase in androgen levels, and that hyperandrogenemia was a risk factor for dyslipidemia. Thus, they recommended that the adolescents suffering from this syndrome had to receive consultation to prevent the long-term complications of the disease. ${ }^{10}$

Polycystic ovarian syndrome has prepubertal origin in a large number of women because its clinical symptoms begin before puberty. This has been supported by detection of morphology of polycystic ovaries and clinical presentations of androgen increase in prepubertal girls. ${ }^{11}$

According to European Society of Human Reproduction and Embryology and American Fertility Association in 2003, having two out of the three of the following criteria was diagnosed as PCOS: (1) oligomenorrhea or amenorrhea, (2) clinical hyperandrogenism or hyperandrogenemia, and (3) polycystic ovaries in ultrasound (more than eight follicles in each ovary) and rejection of other etiologies. ${ }^{12}$ The patients with two or more of the above-mentioned criteria are diagnosed with PCOS. Accordingly, four phenotypes of PCOS can be taken into account: (1) PCOS and clinical hyperandrogenism, (2) PCOS and oligomenorrhea, (3) oligomenorrhea and clinical hyperandrogenism, and (4) PCOS, oligomenorrhea, and clinical hyperandrogenism. ${ }^{13}$ Characteristics of different phenotypes of polycystic ovary syndrome, according to the Rotterdam criteria, 2003, is described in Table $1 .^{14}$

Up to now, a limited number of studies have been conducted on PCOS in adolescents. On the other hand, the complications of this disorder can be prevented by early diagnosis and conservative treatment. Due to the unknown etiology and lack of any specific treatment for PCOS, this disorder is considered as one of the main priorities of preventive medicine in developed countries. Therefore, this study due to the following reasons is the separation of phenotypes of PCOS:

Table 1: Characteristics of different phenotypes of PCOS

\begin{tabular}{|c|c|c|c|}
\hline $\begin{array}{l}\text { Polycystic } \\
\text { ovarian } \\
\text { syndrome } \\
\text { phenotype }\end{array}$ & $\begin{array}{l}\text { Anovulation } \\
\text { (oligomeno- } \\
\text { rrhea) }\end{array}$ & $\begin{array}{l}\text { Hyperandro- } \\
\text { genemia }\end{array}$ & $\begin{array}{l}\text { Polycystic } \\
\text { ovaries in } \\
\text { transvaginal } \\
\text { ultrasonography }\end{array}$ \\
\hline Severe PCOS & + & + & + \\
\hline $\begin{array}{l}\text { Anovulation and } \\
\text { hyperandro- } \\
\text { genemia }\end{array}$ & + & + & - \\
\hline $\begin{array}{l}\text { Ovulatory } \\
\text { PCOS }\end{array}$ & - & + & + \\
\hline Mild PCOS & + & - & + \\
\hline
\end{tabular}

- In a study of adolescent girls with polycystic ovary syndrome, it was concluded that having different phenotypes associated with various metabolic disorders is associated with increased androgen. ${ }^{10}$

- Most studies have examined the overall syndrome ${ }^{13,15-17}$ and few studies have been conducted on the phenotype of the syndrome in Iran.

- In a study, it has been shown that among the four phenotypes PCOS, in the hyperandrogenism and PCOS phenotype, patients had low cholesterol, low-density lipoprotein-cholesterol (LDL-C), total cholesterol and BMI. Then, it was concluded that the lowest risk of cardiovascular disease compared with other phenotypes. ${ }^{18}$ Thus, the present study aimed to compare the levels of androgenic hormones in different phenotypes of PCOS in 14 to 18 years old high school girls in 2009.

\section{MATERIALS AND METHODS}

The present study was approved by the Ethics Committee of Shiraz University of Medical Sciences. This descriptive, cross-sectional study was conducted on 3200 girl students, about 14 and 18 years old, studying in high schools of Shiraz. The research was conducted in the high schools located in different educational districts of Shiraz. This environment was selected because of the availability of 14 to 18 year old girls and having easy access to the research groups. The research community included all the high school students studying in the four educational districts of Shiraz based on the previous studies ${ }^{19}$ and considering confidence interval (CI) of $95 \%, p=3.5 \%$, $\mathrm{d}=0.7 \%, \mathrm{z}=1.96, \alpha=0.05$. Using the following formula, we determined a 2648 subject sample size for the study. Yet, considering the loss rate of $20 \%$, the sample size was increased to 3200 subjects, $\mathrm{n}=\frac{z^{2} \mathrm{p}(1-\mathrm{p})}{\mathrm{d}^{2}}$.

Sampling in the first stage was based on cluster sampling. Between 41 and 16 public high schools were selected as a cluster. In the second stage in each cluster, the girls were selected through simple purposive sampling.

The inclusion criteria of the study were being 14 to 18 years old, being willing to participate in the study and signing written informed consents, not suffering from adrenal and thyroid problems, and not having hyperprolactinemia. On the other hand, the exclusion criteria of the study were not being willing to participate in the study and suffering from diseases, such as thyroid problems, hyperprolactinemia, and adrenal problems, leading to withdrawal from participation in the study.

At first, the researcher explained PCOS and its longand short-term complications to the participants and obtained written informed consents. Then, the participants completed the demographic information questionnaire. 
Afterward, the modified Ferriman-Gallwey scale was used in it, scores $>6$ were considered as hirsutism. ${ }^{20}$ Besides, alopecia was recorded in Ludwig's form based on the androgenic alopecia standards. ${ }^{21,22}$ Finally, acne was classified into weak, average and severe categories. These symptoms were evaluated through examination and interview. Thereafter, the participants suffering from menstrual disorders underwent abdominal ultrasound to determine the existence of cysts. In doing so, the ovaries were scanned in both longitudinal and transverse planes and their volumes were computed using oval's volume formula. The criteria for diagnosis of PCOS in the sonography were similar to those employed by Adams et $\mathrm{al}^{23}$ the most important of which being existence of 10 small peripheral follicles. It should be noted that the sonography specialist was unaware of the patients' clinical examinations and the results of their biochemical tests. Therefore, in case the patients had 10 or more 2 to $8 \mathrm{~mm}$ cysts in the peripheral view or several 2 to $4 \mathrm{~mm}$ cysts in diffuse view, they were diagnosed with PCOS. ${ }^{24,25}$ Also, in case the patients had the clinical or biochemical symptoms of hyperandrogenism or suffered from menstrual disorders together with PCOS and no reasons for androgen increase were detected, PCOS was diagnosed. ${ }^{26,27}$

\section{STATISTICAL ANALYSIS}

The data were analyzed through SPSS statistical software (version 18). For measuring demographic variables, Chi-square and independent sample t-test were used. In addition, the mean levels of hormones were compared through independent sample t-test and Fisher's test. Besides, $\mathrm{p}<0.05$ was considered as statistically significant.

\section{RESULTS}

The mean age of the study population was $16.17 \pm 1.25$; they were mostly aged 17 years (964 patients, 30.2\%) respectively.

Out of 3240 patients, 34 had hypothyroidism, five had elevated prolactin, one had hypothalamic amenorrhea, and 10 had a loss; all of these people were excluded from the study and the results were compared with 3190 students. One hundred and thirty-eight individuals from the population-based on Rotterdam criteria, 2003, PCOS was diagnosed by an endocrinologist (the overall prevalence of the syndrome was $4.32 \%$ ).

In the present study, among of 138 girls with PCOS, 21 presented phenotype 1 (14.4\%), 29 phenotype $2(19.9 \%)$, 45 presented phenotype $3(30.8 \%)$, and 43 presented phenotype 4 (29.5\%) respectively. The mean levels of testosterone, free testosterone, and dehydroepiandrosterone sulfate (DHEAS) were higher in participants with hyperandrogenism and PCOS compared to others, but the difference was not statistically significant $(\mathrm{p}>0.05)$ (Table 2). In addition, the mean levels of testosterone, free testosterone, and DHEAS were significantly higher in participants with hyperandrogenism and oligomenorrhea compared to those without hyperandrogenism and oligomenorrhea $(p<0.05)$ (Tables 3 to 5$)$. According to the

Table 2: Mean of hormonal tests in hyperandrogenism and PCOS phenotype

\begin{tabular}{llll}
\hline & Without $\mathrm{HA}^{*}+$ & With HA & \\
$\begin{array}{l}\text { Phenotype } \\
\text { hormone }\end{array}$ & meOS $^{* *}(n=100)$ & $\begin{array}{l}\text { PCOS }(n=45) \\
\text { phenotype }\end{array}$ & p-value \\
\hline TSH & $3.62 \pm 1.90$ & $3.36 \pm 1.58$ & 0.38 \\
FSH & $5.96 \pm 2.34$ & $6.43 \pm 2.34$ & 0.26 \\
LH & $12.63 \pm 15.18$ & $14.84 \pm 10.66$ & 0.37 \\
PL & $13.27 \pm 4.85$ & $13.12 \pm 4.84$ & 0.86 \\
Testosterone & $0.607 \pm 0.35$ & $0.655 \pm 0.26$ & 0.42 \\
Free & $1.47 \pm 0.81$ & $1.63 \pm 0.57$ & 0.22 \\
testosterone & & & \\
DHEAS & $2.15 \pm 1.35$ & $2.26 \pm 1.24$ & 0.62 \\
\hline
\end{tabular}

Independent sample t-test-HA*: Hyperandrogenism; PCOS**: Polycystic ovarian syndrome; TSH: Thyroid stimulation hormone; FSH: Follicle stimulation hormone; LH: Luteinizing hormone; DHEAS: Dehydroepiandrosterone sulfate

Table 3: Mean of hormonal tests in hyperandrogenism and oligomenorrhea phenotype

\begin{tabular}{llll}
\hline $\begin{array}{l}\text { Phenotype } \\
\text { hormone }\end{array}$ & $\begin{array}{l}\text { Without } \mathrm{HA}^{*}+ \\
\text { oligo** }(n=116) \\
\text { mean } \pm S D\end{array}$ & $\begin{array}{l}\text { With HA + oligo } \\
(n=29) \\
\text { phenotype }\end{array}$ & p-value \\
\hline TSH & $3.56 \pm 1.8$ & $3.51 \pm 1.84$ & 0.90 \\
FSH & $6.27 \pm 2.45$ & $5.43 \pm 1.69$ & 0.08 \\
LH & $13.50 \pm 15.12$ & $12.51 \pm 7.73$ & 0.73 \\
PL & $13.33 \pm 4.99$ & $12.77 \pm 4.174$ & 0.57 \\
Testosterone & $0.596 \pm 0.32$ & $0.726 \pm 0.31$ & 0.05 \\
Free & $1.45 \pm 0.78$ & $0.726 \pm 0.56$ & 0.03 \\
testosterone & & & \\
DHEAS & $2.09 \pm 1.24$ & $2.80 \pm 1.44$ & 0.004 \\
\hline
\end{tabular}

Independent sample t-test-HA*: Hyperandrogenism; Oligo*: Oligomenorrhea; TSH: Thyroid stimulation hormone; FSH: Follicle stimulation hormone; LH: Luteinizing hormone; DHEAS: Dehydroepiandrosterone sulfate

Table 4: Mean of hormonal tests in oligomenorrhea and PCOS phenotype

\begin{tabular}{llll}
\hline & Without oligo* & With oligo + & \\
Phenotype & $P$ COS $^{* *}(n=102)$ & PCOS $(n=43)$ & \\
hormone & mean $\pm S D$ & phenotype & $p$-value \\
\hline TSH & $3.46 \pm 1.79$ & $3.75 \pm 1.84$ & 0.38 \\
FSH & $6.05 \pm 2.61$ & $6.23 \pm 1.51$ & 0.61 \\
LH & $13.14 \pm 15.86$ & $13.70 \pm 7.80$ & 0.82 \\
PL & $13.50 \pm 5.07$ & $12.55 \pm 4.18$ & 0.28 \\
Testosterone & $0.575 \pm 0.30$ & $0.732 \pm 0.37$ & 0.01 \\
Free & $1.38 \pm 0.73$ & $1.82 \pm 0.72$ & 0.001 \\
testosterone & & & \\
DHEAS & $2.09 \pm 1.35$ & $2.40 \pm 1.21$ & 0.18 \\
\hline
\end{tabular}

Independent sample t-test-Oligo*: Oligomenorrhea; PCOS**: Polycystic ovarian syndrome; TSH: Thyroid stimulation hormone; FSH: Follicle stimulation hormone; LH: Luteinizing hormone; DHEAS: Dehydroepiandrosterone sulfate 
Table 5: Mean of hormonal tests in oligomenorrhea hyperandrogenism and PCOS phenotype

\begin{tabular}{|c|c|c|c|}
\hline $\begin{array}{l}\text { Phenotype } \\
\text { hormone }\end{array}$ & $\begin{array}{l}\text { Without oligo* }+ \\
H A^{* *} P C O S^{* * *} \\
(n=124) \\
\text { mean } \pm S D\end{array}$ & $\begin{array}{l}\text { Without oligo* }+ \\
H A^{* *} P C O S^{* * *} \\
(n=21) \\
\text { phenotype }\end{array}$ & $p$-value \\
\hline TSH & $3.56 \pm 1.83$ & $3.50 \pm 1.69$ & 0.89 \\
\hline FSH & $6.17 \pm 2.43$ & $5.71 \pm 1.70$ & 0.41 \\
\hline $\mathrm{LH}$ & $13.23 \pm 4.77$ & $13.77 \pm 7.62$ & 0.86 \\
\hline PL & $13.27 \pm 4.89$ & $12.92 \pm 4.56$ & 0.76 \\
\hline Testosterone & $0.59 \pm 0.33$ & $0.75 \pm 0.26$ & 0.03 \\
\hline $\begin{array}{l}\text { Free } \\
\text { testosterone }\end{array}$ & $1.44 \pm 0.76$ & $1.92 \pm 0.51$ & 0.007 \\
\hline DHEAS & $2.08 \pm 1.29$ & $2.76 \pm 1.36$ & 0.02 \\
\hline
\end{tabular}

Independent sample t-test-Oligo*: Oligomenorrhea; HA*: Hyperandrogenism; $\mathrm{PCOS}^{* * *}$ : Polycystic ovarian syndrome; TSH: Thyroid stimulation hormone; FSH: Follicle stimulation hormone; LH: Luteinizing hormone; DHEAS: Dehydroepiandrosterone sulfate

results, 670 subjects $(12 \%)$ had menstrual disorders, while 2615 subjects $(83.4 \%)$ had normal menstruation. Besides, 144 subjects $(4.6 \%)$ suffered from oligomenorrhea. Polycystic ovarian syndrome was detected in $60.6 \%$ of the adolescents with abnormal menstrual cycles and $16.9 \%$ of those with normal cycles. The symptoms of PCOS were also observed in $29.5 \%$ of the participants with oligomenorrhea.

\section{DISCUSSION}

Ovarian hyperandrogenism is one of the main symptoms of PCOS. In general, ovaries produce great amounts of androstenedione and dehydroepiandrostenedione, but increase in serum testosterone is more common. The chemical symptoms of this syndrome include increase of LH level, increase of LH/FSH ratio to above 2.5, increase of androgen levels (testosterone and androstenedione), and insulin resistance. ${ }^{28}$

The results of the current study showed higher androgenic hormone levels in the three phenotypes with oligomenorrhea. Other research has also indicated that PCOS and increase in serum androgens were more prevalent among the adolescents with menstrual disorders. ${ }^{29-31}$ Nonetheless, some studies have reported normal menstruations accompanied by PCOS. ${ }^{31,32}$ Gil Junior et al conducted a study on the level of androgens secreted by the women with PCOS and revealed that $81.1 \%$ had biochemical hyperandrogenism and $62.2 \%$ had adrenal hyperandrogenism. ${ }^{33}$

The main cause of oligomenorrhea is hormonal disorders, such as an ovulation. The diseases leading to increase in androgen levels, including adrenal hyperplasia, PCOS, hyperprolactinemia, and thyroid disorder can also result in oligomenorrhea and signs, such as hirsutism and acne. ${ }^{8}$ Nonetheless, even mild androgen disorders require treatment interventions. Since these disorders can be risk factors for diabetes, endometrial and breast cancer, cardiovascular disorders, and cerebrovascular diseases, ${ }^{34}$ identification of these patients and determination of their prevalence rates are of great importance. Moreover, considering the fact that PCOS is one of the major causes of oligomenorrhea, accurate examination of the patients with oligomenorrhea regarding PCOS can contribute to timely diagnosis and treatment. Jonathan et al (2002) performed a study on 100 women below 35 years old who suffered from oligomenorrhea and reported PCOS in $51 \%$ of the participants. ${ }^{35}$ In the study by Panidis et al (2012), phenotype 1 among other phenotypes of PCOS was the most common (48.2\%) phenotype. ${ }^{14}$ The studies by Dewailly et al (2006) and Guastella et al (2010) reading, but in our study phenotype 3 was more common. ${ }^{36,37}$

In the present study, PCOS was detected in $60.6 \%$ of the adolescents with abnormal menstrual cycles compared to $16.9 \%$ of those with normal cycles. Farquhar et al (1994) carried out a research on 255 healthy women and reported the prevalence of PCOS to be $21 \%$ through ultrasound. This puts using sonography for diagnosis of PCOS in doubt. ${ }^{38}$

In the study by Aali et al (2002), the specific view of PCOS was detected in 106 patients (81.5\%). ${ }^{39}$ Besides, Khoury et al reported polycystic ovaries in $69 \%$ of the patients. ${ }^{40}$ Additionally, Van Hooff conducted a study in 2000 and showed PCOS in $28 \%$ of the girl adolescents with abnormal menstrual cycles compared to $9 \%$ of those with normal cycles. Also, PCOS was observed in $45 \%$ of the patients with oligomenorrhea. ${ }^{41}$ The difference in the above-mentioned measures can be attributed to the difference in length and features of the disease.

The findings of the present study demonstrated higher blood levels of total testosterone, free testosterone, and dehydroepiandrostenedione in patients with oligomenorrhea compared to those with normal menstrual cycles.

In the study by Huang et al also, free testosterone $(57.6 \%)$, total testosterone (33\%), and dehydroepiandro stenedione $(32.7 \%)$ increased in the women suffering from PCOS compared to the noninfected individuals. ${ }^{42}$

Van Hooff et al (1999) conducted a research on 2248 girl students about 14 to 17 years old with a mean age of $15.6+0.6$ years to investigate the relationship between endocrine symptoms of PCOS and menstrual disorders. The study results indicated higher blood levels of LH, androstenedione, testosterone, DHEAS, and estradiol in the girls who suffered from oligomenorrhea compared to those with normal menstrual cycles. However, no significant hormonal difference was observed between the patients with other menstrual disorders, such as polymenorrhea and metrorrhagia, and those with normal menstrual cycles. ${ }^{30}$ 
In the study by Głuszak et al, the most prevalent phenotype of PCOS $(60.2 \%)$ was type I phenotype (oligomenorrhea, hyperandrogenism and PCOS), and menstrual disorders were observed in 3 out of 4 phenotypes of this syndrome. ${ }^{3}$ Also, in the study by Panidis et al, testosterone levels in the circulation were more than in the phenotype. One but a number of other studies have not confirmed the issue(s) and there have been no differences in testosterone levels in 4 phenotypes. In our study, testosterone levels were higher in the phenotype $1,2,4$ compared to phenotype 3 . $^{17,36,37,43,44}$

Although insulin resistance was not discussed in our paper, the increase in polycystic ovary syndrome and some phenotypes of PCOS is important. Now insulin resistance (IR) is known as one of the major risk factors for type 2 diabetes mellitus. ${ }^{45}$

Even in nonobese women with PCOS, IR amounts to a slight increase. Approximately, 50 to $70 \%$ of women with PCOS have shown some degrees of insulin resistance. ${ }^{46-49}$ The resistance can lead to obesity or it is independent of and associated with hyperandrogenism. Increased blood insulin directly effects the vascular endothelial cells and individuals with insulin resistance and metabolic syndrome are predisposed to vascular thrombosis. ${ }^{50,51}$

A previous study assessed the relationship between menstrual disorders and body mass index (BMI) and existence of polycystic ovaries in sonography in 15 years old adolescents with stable oligomenorrhea cycles up to the age of 18 years. The study findings revealed that the best predictor of oligomenorrhea cycles at the ages of 18 and above was menstrual disorders 1 year after menarche. They also stated that diagnostic value of menstrual disorders at the beginning of menarche was higher than that of high androgen and LH levels or existence of polycystic ovaries in ultrasound..$^{52}$ Therefore, it can be concluded that the diseases associated with androgen increase, such as PCOS, can lead to oligomenorrhea and other accompanying symptoms, such as hirsutism and acne.

In this study, androgenic hormone levels were higher in the phenotypes of PCOS with menstrual disorders, particularly oligomenorrhea. In a study which was conducted on 1002 women aged 18 and 45 years in Tehran, the prevalence of PCOS was $8.5 \%$, and $13 \%$ of the women had menstrual disorders. They concluded that LH disorders and PCOS were the most common endocrine disorders in women at reproductive ages. ${ }^{53}$

Oligomenorrhea after menarche can be the beginning of ovulation problems, infertility, and abnormal increase in estrogen and androgens in the years to come. In one study, $21 \%$ of the women with hyperandrogenism and regular menstrual cycles showed anovulation. ${ }^{36}$

\section{CONCLUSION}

The mean levels of testosterone, free testosterone and DHEAS were higher in various phenotypes of PCOS compared to the control group. However, a significant relationship was observed in hyperandrogenism and oligomenorrhea phenotype. Furthermore, in comparison to other symptoms of hyperandrogenism and ultrasound, menstrual disorder was more important in PCOS. Thus, serum androgenic levels are recommended to be measured in young girls with menstrual disorders, so that the necessary measures can be taken for early diagnosis of this syndrome and the necessary preventive measures.

\section{ACKNOWLEDGMENTS}

Hereby, the authors would like to thank the Endocrine and Metabolism Research Center of Nemazee Hospital for their cooperation. The authors would also like to thank $\mathrm{Dr}$ Nasrin Shokrpour at Center for Development of Clinical Research of Nemazee Hospital for editorial assistance.

\section{REFERENCES}

1. Guo M, Chen ZJ, Eijkemans MJ, Goverde AJ, Fauser BC, Macklon NS. Comparison of the phenotype of Chinese versus Dutch Caucasian women presenting with polycystic ovary syndrome and oligo/amenorrhoea. Hum Reprod 2012;27(5):1481-1488.

2. Akbarzadeh M, Moradi F, Dabbaghmaneh $\mathrm{MH}$, Parsanezhad ME, Jafary P. A survey of metabolic syndrome in first-degree relatives (fathers) of patients with polycystic ovarian syndrome, JEMDSA 2013;18(2):98-103.

3. Głuszak O, Stopińska-Głuszak U, Glinicki P, Kapuścińska R, Snochowska $\mathrm{H}$, et al. Phenotype and metabolic disorders in polycystic ovary syndrome. International Scholarly Research Network. ISRN Endocrinol 2012;569862. DOI: 10.5402/2012/569862.

4. Hwang KR, Choi YM, Kim JJ, Chae SJ, Park KE, Jeon HW, KuSY, Kim SH, Kim JG, Moon SY. Effects of insulin-sensitizing agents and insulin resistance in women with polycystic ovary syndrome. Clin Exp Reprod Med. 2013;40(2):100-105.

5. Rizzo M, Berneis K, Hersberger M, Pepe I, Di Fede G, Rini GB, Spinas GA, Carmina E. Milder forms of atherogenic dyslipidemia in ovulatory versus anovulatory polycystic ovary syndrome phenotype. Hum Reprod 2009;24(9): 2286-2292.

6. Joshi B, Mukherjee S, Patil A, Purandare A, Chauhan S, Vaidya R. A cross-sectional study of polycystic ovarian syndrome among adolescent and young girls in Mumbai, India. Indian J Endocrinol Metab 2014 May;18(3):317-324.

7. Mehrabian F, Khani B, Kelishadi R, Ghanbari E. The prevalence of polycystic ovary syndrome in Iranian women based on different diagnostic criteria. Endokrynol Pol 2011;62(3):238-242.

8. Christopher R, Mc Cartney, Kathleen A. The Association of obesity and hyperandrogenemia during the pubertal transition in girls. J Clin Endocrin Metabolism 2005;91(5): 1714-1722. 
9. Chhabra S, McCartney CR, Yoo RY, Eagleson CA, Chang RJ, Marshall JC. Progesterone inhibition of the hypothalamic gonadotropin-releasing hormone pulse generator: evidence for varied effects in hyperandrogenic adoplescent girls. J Clin Endocrinol Metab 2005;90(5):2810-2815.

10. Fruzzetti F, Perini D, Lazzarini V, Parrini D, Genazzani AR. Adolescent girls with polycystic ovary syndrome showing different phenotypes have a different metabolic profile associated with increasing androgen levels. Fertil Steril 2009; 92(2):626-634.

11. Rosenfield RL. Identifying children at risk for polycystic ovary syndrome. J Clin Endocrinol Metab 2007;92(3):787-796.

12. Rotterdam ESHRE/ASRM-sponsored PCOS Consensus Workshop Group. Revised 2003 consensus on diagnostic criteria and long-term health risks related to polycystic ovary syndrome. Fertil Steril 2004;81(1):19-25.

13. Chae SJ, Kim JJ, Choi YM, Hwang KR, Jee BC, Ku SY, et al. Clinical and biochemical characteristics of polycystic ovary syndrome in Korean women. Hum Reprod 2008 Aug;23(8): 1924-1931.

14. Panidis D, Tziomalos K, Misichronis G, Papadakis E, Betsas G, Katsikis I, et al. Insulin resistance and endocrine characteristics of the different phenotypes of polycystic ovary syndrome: a prospective study. Hum Reprod 2012 Feb;27(2):541-549.

15. Diamanti-Kandarakis E, Panidis D. Unravelling the phenotypic map of polycystic ovary syndrome (PCOS): a prospective study of 634 women with PCOS. Clin Endocrinol (Oxf) 2007;67(5):735-742.

16. Pehlivanov B, Orbetzova M. Characteristics of different phenotypes of polycystic ovary syndrome in a Bulgarian population. Gynecol Endocrinol Gynecol Endocrinol 2007; 23(10):604-609.

17. Shroff R, Syrop CH, Davis W, Van Voorhis BJ, Dokras A. Risk of metabolic complications in the new PCOS phenotype based on the Rotterdam criteria. Fertil Steril 2007;88(5):1389-1395.

18. Dilbaz B, Ozkaya E, Cinar M, Cakir E, Dilbaz S. Cardiovascular disease risk characteristics of the main polycystic ovary syndrome phenotypes. Endocrine 2011 Jun;39(3):272-277.

19. Hashemipour M, Faghihimani S, Zolfaghary B, Hovsepian S, Ahmadi F, Haghighi S. Polycystic ovary syndrome in girls aged 14-18 years in Isfahan, Iran. Horm Res 2004;62(6): 278-282.

20. Ferriman D, Gallwey JD. Clinical assessment of body hair growth in women. Endocr Rev 2000;21(4):347-362.

21. Ludwig E. Classification of the types of androgenetic alopecia (common baldness) occurring in the female sex. Br J Dermatol 1977 Sep;97(3):247-257.

22. Berek JS, Adashi EY, Hillard PA, Novak S. Gynecology. 13th ed. Philadelphia: Waverly; 2007. p. 149-172.

23. Adams J, Polson DW, Franks S.. Prevalence of polycystic ovaries in women with idiopathic hirsutism. Br Med J (Clin Res Ed). 1986;9;293(6543):355-359.

24. Swanton A, Storey L, McVeigh E, Child T. IVF outcome in women with PCOS, PCO and normal ovarian morphology. Eur J Obstet Gynecol Reprod Biol 2010;149(1):68-71.

25. Takahashi K, Eda Y, Abu-Musa A, Okada S, Yoshino K, Kitao M. Trasvaginal ultasound imaging, histopatology and endocrinopathy in patient with polycystic ovarian syndrome. Hum Reprod 1994;9(7):1231-1236.

26. Ehrmann DA. Polycystic ovary syndrome. N Engl J Med 2005 Mar 24;352(12):1223-1236.
27. Hershlay A, Peterson M. Endocrin Disorder. Novak's Gynecology. In: Berek JS, editor. Lippincott Williams \& Wilkins; 2002. p. 871-917.

28. de Ziegler D1, Steingold K, Cedars M, Lu JK, Meldrum DR, Judd HL, et al. Recovery of hormon secretion after chronic gonadotropin-releasing hormon agonist administration in women with PCO disease. J Clin Endocrinol Metab 1989;68(6):1111-1117.

29. Lobo RA, Goebelsmann U, Horton R. Evidence for the importance of peripheral tissue events in the development of hirsutism in polycystic ovary syndrome. J Clin Endocrinol Metab, 1983;57(2):393-397.

30. van Hooff $\mathrm{MH}$, Voorhorst FJ, Kaptein MB, Hirasing RA, Koppenaal C, Schoemaker J. Polycystic ovaries in adolescents and the relationship with menstrual cycle patterns, luteinizing hormon, androgens and insulin. Fertil Steril, 2000;74(1):49-58.

31. Apter D. How possible is the prevention of PCO develope in adolescent patients with early onset of hyperandrogenism. Endocrinol Invest 1998;21(9):613-617.

32. Androulakis II, Kandaraki E, Christakou C, Karachalios A, Marinakis E, Paterakis T, et al. Visceral adiposity index (VAI) is related to the severity of anovulation and other clinical features in women with polycystic ovary syndrome. Clin Endocrinol (Oxf) 2014 Sep;81(3):426-431.

33. Gil Junior AB, Rezende AP, do Carmo AV, Duarte EI, de Medeiros MM, de Medeiros SF. [Adrenal androgen participation in the polycystic ovary syndrome]. Rev Bras Ginecol Obstet 2010 Nov;32(11):541-548.

34. Ovalle F, Aziz R. Insulin resistance, polycystic ovary syndrome, and type 2 diabetes mellitus. Fertility and sterility 2002;77(6):1095-1105.

35. Jonatan S, Berek F, Paoulo A. Novak 's gynecology, 12th ed, Philadelphia, Lippincott Williams \& Wilkins ;2002. p. 158-160.

36. Dewailly D, Catteau-Jonard S, Reyss AC, Leroy M, Pigny P. Oligoanovulation with polycystic ovaries but not overt hyperandrogenism. J Clin Endocrinol Metab 2006 Oct;91(10): 3922-3927.

37. Guastella E, Longo RA, Carmina E. Clinical and endocrine characteristics of the main polycystic ovary syndrome phenotypes. Fertil Steril 2010;94(6):2197-2201.

38. Farquhar CM, Birdsall M, Manning P, Mitchell JM, France JT. The prevalence of the polycystic ovaries on ultrasound scanning in a population of randomly selected women. Aust NZ J Obstet Gynaecol 1994;34(1):67-72.

39. Aali SH , Naderi T. Clinical characteristics, laboratory and ultrasound polycystic ovary syndrome in Kerman. Journal of Endocrinology and Metabolism University of Medical Sciences and Health Services Beheshti 2004;6(2):153-161. (persion)

40. Khoury MY, Baracat EC, Pardini DP, Haidar MA, da Motta EL, de Lima GR. Polycystic ovarian syndrome: clinical and laboratory evaluation. Sao Paulo Med J 1996;114(4):1222-1225.

41. Van Hooff MHA, Voorhorst FJ, Kaptein MBH, Hirasing RA, Koppenaal C, Schoemaker J. Endocrine features of polycystic ovary syndrome in an random population sample of 14-16 years old adolescents. Hum reprod 1999;14(9):2223-2229.

42. Huang A, Brennan K, Azziz R. Prevalence of hyperandrogenemia in the polycystic ovary syndrome diagnosed by the National Institutes of Health 1990 criteria. Fertil Steril 2010;93(6):1938-1941. 
43. Hahn S, Bering van Halteren W, Roesler S, Schmidt M, Kimmig R, Tan S, et al. The combination of increased ovarian volume and follicle number is associated with more severe hyperandrogenism in German women with polycystic ovary syndrome. Exp Clin Endocrinol Diabetes 2006 Apr;114(4): 175-181.

44. Legro RS, Chiu P, Kunselman AR, Bentley CM, Dodson WC, Dunaif A. Polycystic ovaries are common in women with hyperandrogenic chronic anovulation but do not predict metabolic or reproductive phenotype. J Clin Endocrinol Metab 2005 May;90(5):2571-2579.

45. Baillargeon JP. Use of insulin sensitizers in polycystic ovarian syndrome. Curr Opin Investig Drugs 2005 Oct;6(10):1012-1022.

46. Benttez R, Manint P, Palomino A, Angel B, Maliqmeo M, Perez $\mathrm{F}$, et al. Prevalence of metabolic disorders among family member of patiens with polycystic ovary syndrome. The Journal of Review Medical Chil 2001;129(7):707-712.

47. Norman RJ, Masters S, Hague W. Hypernisulinemia is common in family members of women with polcystic ovary syndrome. Fertil Steril 1996 Dec;66(6):942-947.

48. Yildiz BO, Yarali H, Oguz H, Bayraktar M.Glucose intolerance, insulin resistance and hyprandrogenemia in first degree relatives of woman with polycystic ovary syndrome. J Clin Endocrinol Metab 2003;88(5):2031-2036.

49. Akbarzadeh M, Moradi F, Dabbagh Manesh M, Zareh N, Parsa Nezhad M. Insulin resistance in first-degree relatives of the patients with polycystic ovarian syndrome. IJDO 2013;5(4):163-170.

50. Lindblad U, Langer RD, Wingard DL, Thomas RG, BarrettConnor EL. Metabolic syndrome and Ischemic heart disease in elderly men and women. Am J Epidemiol 2001 Mar 1;153(5):481-489.

51. Sanisoglu SY, Oktenli C, Hasimi A, Yokusoglu M, Ugurlu M. Prevalence of metabolic syndrome related disorder in a large adult population in Turkey. BMC Public Health 2006 Apr10;6:92.

52. Salardi S, Orsini LF, Cacciari E, Bovicelli L, Tassoni P, Reggiani A. Premenarcheal endocrine change in relation to age at menarche. Clin Endocrinol (Oxf) 1985;22(6):753-760.

53. Tehrani FR, Rashidi H, Azizi F. The prevalence of idiopathic hirsutism and polycystic ovary syndrome in the Tehran Lipid and Glucose Study. Reprod Biol Endocrinol 2011 Nov; 9:144. 